\title{
Growth Curves of Alexandrian Infants
}

\author{
Hanan M. Abd El Aziz*
}

\begin{abstract}
The objective of this article is to construct infants growth curves of weight-for-age and length-for-age for Alexandria infants, (0-2 years) and to compare the WHO Child Growth Standards (2006) and the current constructed curves. The study was carried out through a cross sectional approach, at maternal and child health centers (MCH) in Alexandria (Egypt), it included sample of infants aged less than two years (1-24 months). Data was presented graphically by Z-scores and percentiles. The results showed that, the mean weight for age of infants included in the WHO standards was below the present median during early months of infancy. Based on the -2SD cut-off point, the prevalence of underweight was higher during the twenty four months for both girls and boys based on the present curves. The average length of infants included in the present study was above the WHO standards median during the first half of infancy. Moreover, for all age groups, stunting rates (i.e., <-2SD) were higher when based on the present sample curves, especially after one year of age. Infants of the first year of life in the present curve were taller than those in the WHO standard ( $>+2 \mathrm{SD}$ ). Conclusion and Recommendations: A reference based on healthy breastfed infants is required if the growth patterns of infants following international feeding recommendations are to be correctly assessed. So, the WHO 2006 curves for age 0 to 24 months, based on longitudinal data, are the best choice.
\end{abstract}

Key words: Growth Charts, WHO Standards, Infancy, Stunting, Over Weight, Under Weight, Percentiles, Z-Score, Weight For Age, Height For Age

\section{INTRODUCTION}

Growth charts are an essential However, their usefulness goes far beyond component of the pediatric toolkit. Their assessing children's nutritional status. value resides in helping to determine the Many governmental and United Nations degree to which physiological needs for agencies rely on growth charts for growth and development are being met measuring the general well-being of during the important childhood period.(1) populations, formulating health and related

\footnotetext{
${ }^{\star}$ Family Health Department, High Institute of Public Health, Alexandria University,
} 
policies, and planning interventions and monitoring their effectiveness. ${ }^{(2,3)}$

The origin of the WHO Child Growth Standards dates back to the early 1990s, when there was the appointment of a group of experts to conduct a meticulous evaluation of the National Center for Health Statistics/World Health Organization (NCHS/WHO) growth reference, which had been recommended for international use since the late 1970s. The review concluded that, it did not adequately represent early childhood growth and that new growth curves were necessary. ${ }^{(3-5)}$

In April 2006 the WHO released new standards for assessing the growth and development of children from birth to 5 years of age. The new standards adopt a fundamentally prescriptive approach designed to describe how all children should grow rather than the more limited goal of describing how children grew at a specified time and place. $(6,7)$ The experts underscored the importance of ensuring that the new growth charts were consistent with "best" health practices. ${ }^{(5)}$

In the last three decades, countless studies have measured child nutritional status in developing countries using as reference growth charts introduced in 1977.(8-12) Over the past 35 years, Egyptian demographic and survival indicators have show marked improvement in child health. Despite these improvements, one of the most serious health concerns is under-nutrition. While there are decreases in levels of child under-nutrition, approximately $7 \%$ under the age of 5 years was under-weight and $18 \%$ was under-height for age- according to the $1977 \mathrm{NCHS}$ reference, these levels still high compared to the international statistics. ${ }^{(10)}$

This article aimed to construct infants growth curves of weight-for-age and length-for-age for Alexandria infants, (02years), and to compare the WHO Child Growth Standards (2006) and the current 
constructed curves.

Subjects and Methods:

The study was carried out through a cross sectional approach, at maternal and child health centers $(\mathrm{MCH})$ in Alexandria (Egypt), it included sample of 2000 infants aged less than two years (1-24 months). Infants were recruited from six $\mathrm{MCH}$ centers. One center was randomly chosen from each of the six health zones in Alexandria Governorate. All single term birth and apparently healthy infants attended the well baby-clinic of these centers during a period of six weeks were included in the study. The age of the child was confirmed through reviewing the birth certificate. Mothers were interviewed using a designed questionnaire to collect data regarding current breast feeding practices.

\section{Anthropometric measurements and} indices:

Weight was measured using a spring scale $(100 \mathrm{~g}$ increments), regularly calibrating, and to the nearest $10 \mathrm{gm}$.
Length was measured supine using graduated plastic mats $(0.5 \mathrm{~mm}$ increments).

Data exported to the Microsoft Excel 2003 program to construct the graphs, using $x y$ section plot when: $x$; for the whole age, $y$; weight/ length (best fit value). Data was presented graphically by Z-scores and percentiles. Z-scores represent the difference between the length or weight of a child and the median height or weight of the reference population (for the same age and sex) divided by the standard deviation of the reference population. Global stunting and underweight were defined as lengthfor-age and weight-for-age, <-2 z-scores respectively. ${ }^{(13)}$

The percentile is the value below which lays certain percent of the ordered observations. The $10^{\text {th }}, 25^{\text {th }}, 50^{\text {th }}, 75^{\text {th }}$ and $90^{\text {th }}$ percentiles were computed for weightfor- age and length-for-age. All percentiles were smoothed using the best fit model chosen from eleven curve fit equations. For 
all percentiles the best fit equation was the cubic model.

WHO Child Growth Standards (2006):

The WHO standards are based on primary data collected through the WHO Multicentre Growth Reference Study (MGRS). The MGRS was a populationbased study conducted between 1997 and 2003 in Brazil, Ghana, India, Norway, Oman and the USA. The study combined a longitudinal follow-up from birth to 24 months with a cross-sectional component of children aged 18-71 months. The study populations lived in socioeconomic conditions favorable to growth. The individual inclusion criteria were: no known health or environmental constraints to growth, mothers willing to follow MGRS feeding recommendations (i.e., exclusive or predominant breast-feeding for at least 4 months, introduction of complementary foods by 6 months of age, and continued breast-feeding to at least 12 months of age), single term birth, and absence of significant morbidity. (14) Characteristics of the MGRS populations and data collection methods have been published. The final sample and the methods used to develop the standards are also described elsewhere.(15) Weight-for-age and lengthfor-age. Percentiles and Z-score values were generated for boys and girls aged 024 months.

\section{Results:}

At the time of the interview, more than half of the infants $(51.3 \%)$ were complementary breast-fed, while $26.0 \%$ were formula-fed.

Figures $(1,2)$ present the percentile curves of the weight for both sexes. The curve shows that, there is an exponential relationship of weight with age. The male curve starts higher than the female one, and continue higher up to 24 months. The median percentile ranged from $5-10.5 \mathrm{~kg}$ and from $5.5-11 \mathrm{~kg}$ for females and males respectively.

Figures $(3,4)$ present the percentile 
curves of the length for both sexes. The median curve shows that, the male curve starts higher than the female one, and continue higher up to 24 months. The $3^{\text {rd }}$ and $10^{\text {the }}$ percentile curves show a distinct fall in the rate of growth in the period from approximately 18 months for female percentile

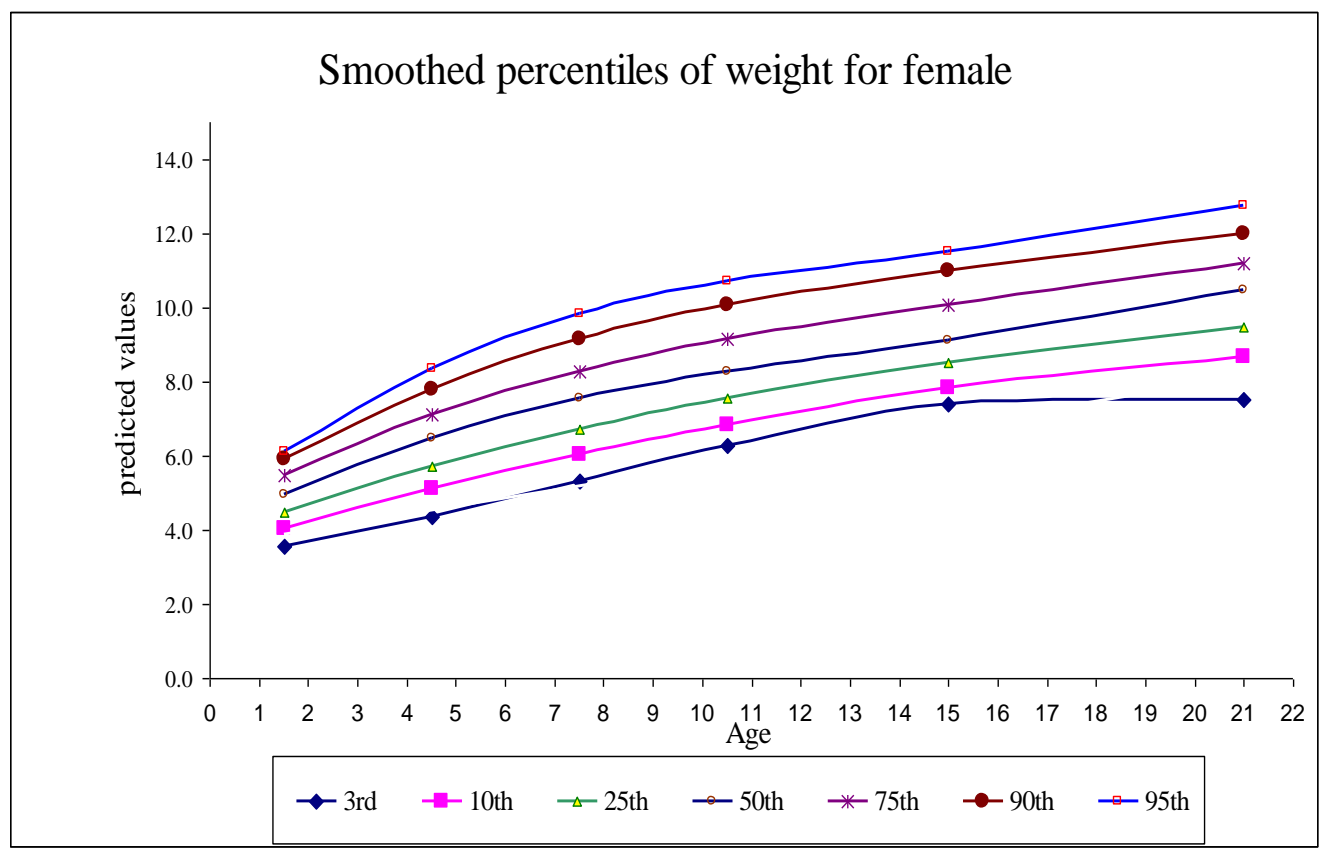

Figure (1): Smoothed percentiles of weight for female by age. 


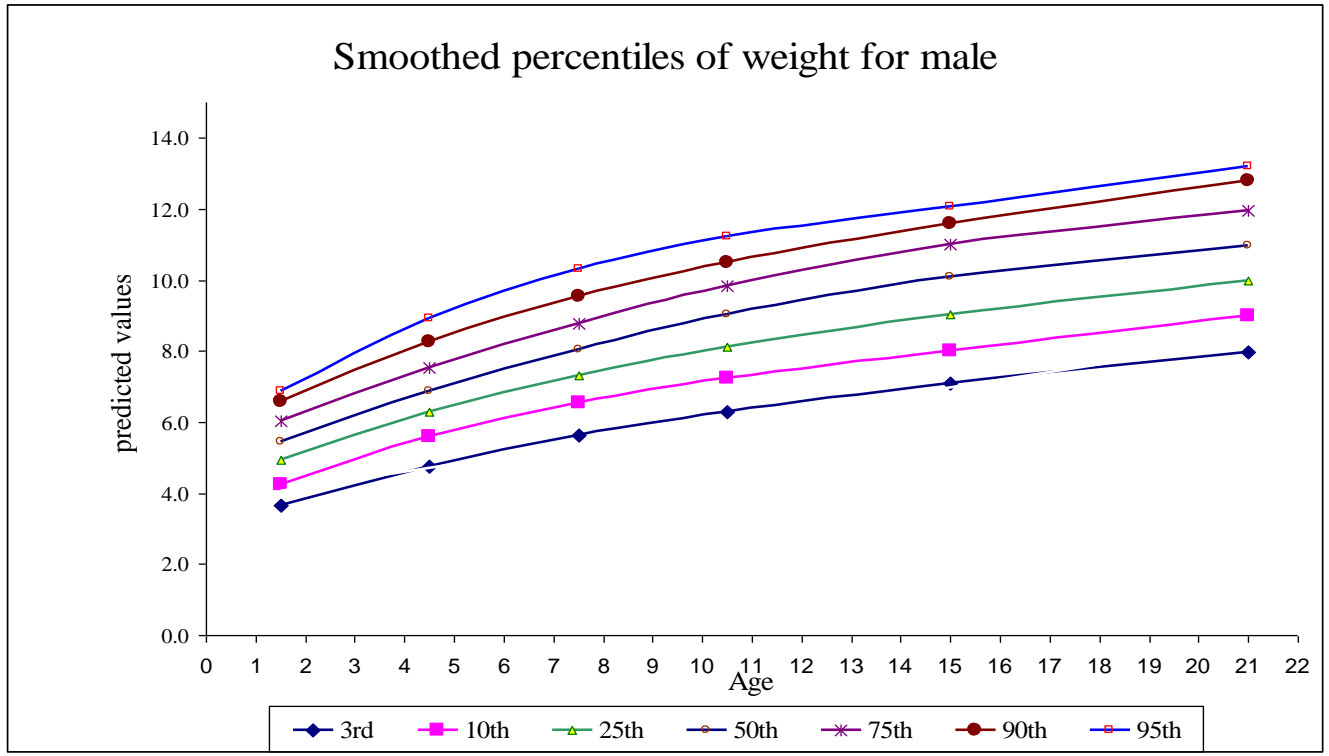

Figure (2): Smoothed percentiles of weight for male by age.

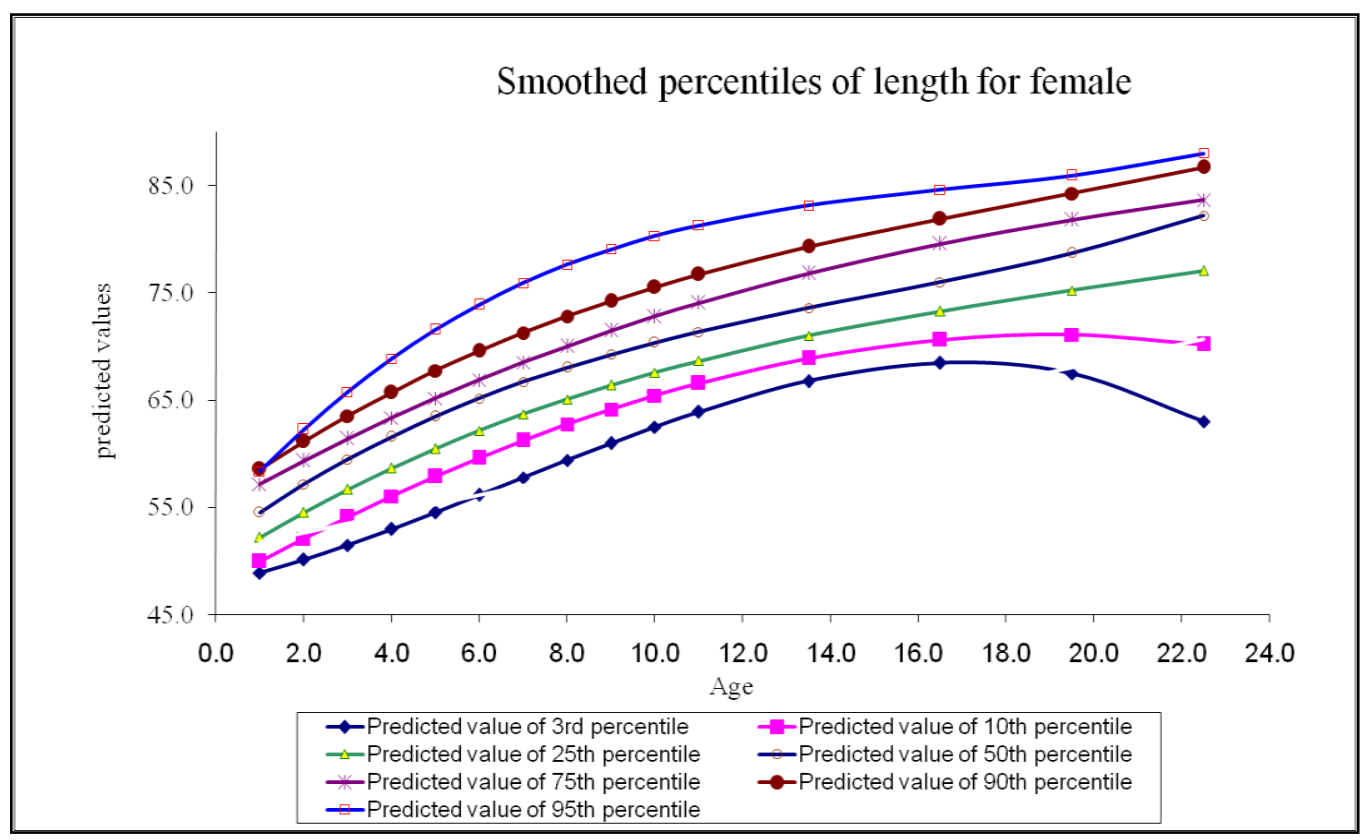

Figure (3): Smoothed percentiles of length for female by age. 


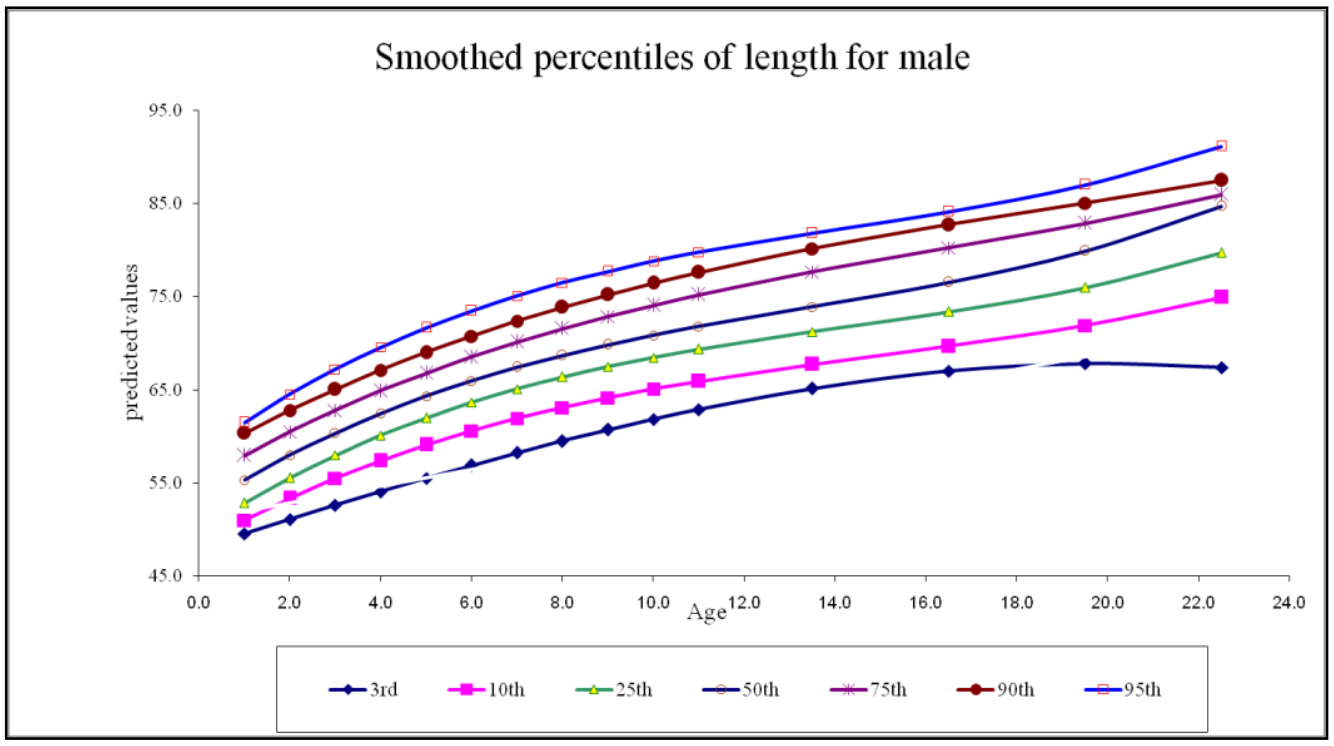

Figure (4): Smoothed percentiles of length for male by age.

Tables $(1,2) \&$ figure 5,6 compare the WHO and the present weight-for-age -Zscore curves for girls and boys. The mean weight of infants included in the $\mathrm{WHO}$ standards was below the present median during early months of infancy, crossed it at $\approx$ two months, and tracked above thereafter. Based on the -2SD cut-off point, the prevalence of underweight was higher during the twenty four months for both girls and boys based on the present curves. On the other hand, the present $(+2 S D)$ curve was higher for boys all through 24 month, while, it was higher only among the first year of infancy for girls. Overall, the present sample seems to be heavier.

Tables $(3,4)$ \& figure 7,8 compare the WHO and the present length-for-age -Zscore curves for girls and boys. The average length of infants included in the present study was above the WHO standards median during the first half of infancy, crossed it at about six months, after which the medians overlap until the 
age one year, and tracked below thereafter for both girls and boys. For all age groups, stunting rates (i.e., < -2SD) were higher when based on the present curves, (>+2SD). especially after one year of age. Infants of the first year of life in the present curve were taller than those in the WHO standard

Table (1): Comparison of the WHO and the present weight-for-age Z-score curves for girls.

\begin{tabular}{|c|c|c|c|c|c|c|}
\hline \multicolumn{7}{|c|}{ Smoothed weight for age of girls } \\
\hline \multirow{2}{*}{ Age } & \multicolumn{3}{|c|}{ Alexandria } & \multicolumn{3}{c|}{ WHO } \\
\cline { 2 - 7 } & -2 SD & Mean & $+2 S D$ & -2 SD & Mean & +2 SD \\
\hline $1-$ & 3 & 5 & 7 & 4 & 5 & 6 \\
\hline $3-$ & 4 & 7 & 9 & 5 & 7 & 9 \\
\hline $6-$ & 5 & 8 & 10 & 6 & 8 & 10 \\
\hline $9-$ & 6 & 8 & 11 & 7 & 9 & 11 \\
\hline $12-$ & 7 & 9 & 12 & 8 & 10 & 12 \\
\hline $18-24$ & 7 & 10 & 14 & 9 & 11 & 14 \\
\hline
\end{tabular}

Table (2): Comparison of the WHO and the present weight-for-age Z-score curves for boys.

\begin{tabular}{|c|c|c|c|c|c|c|}
\hline & \multicolumn{5}{|c|}{ Smoothed weight for age of boys } \\
\hline \multirow{2}{*}{ Age } & \multicolumn{5}{|c|}{ Alexandria } & \multicolumn{3}{c|}{ WHO } \\
\cline { 2 - 7 } & $-2 S D$ & Mean & $+2 S D$ & $-2 S D$ & Mean & $+2 S D$ \\
\hline $1-$ & 3.6 & 5.5 & 7.3 & 3.7 & 4.9 & 6.1 \\
\hline $3-$ & 4.6 & 6.9 & 9.2 & 5.8 & 7.3 & 8.8 \\
\hline $6-$ & 5.5 & 8.1 & 10.7 & 6.8 & 8.5 & 10.2 \\
\hline $9-$ & 6.2 & 9 & 11.7 & 7.5 & 9.3 & 11.1 \\
\hline $12-$ & 7.1 & 9.9 & 12.8 & 8.3 & 10.3 & 12.3 \\
\hline $18-24$ & 7.7 & 10.9 & 14.2 & 9.2 & 11.5 & 13.6 \\
\hline
\end{tabular}




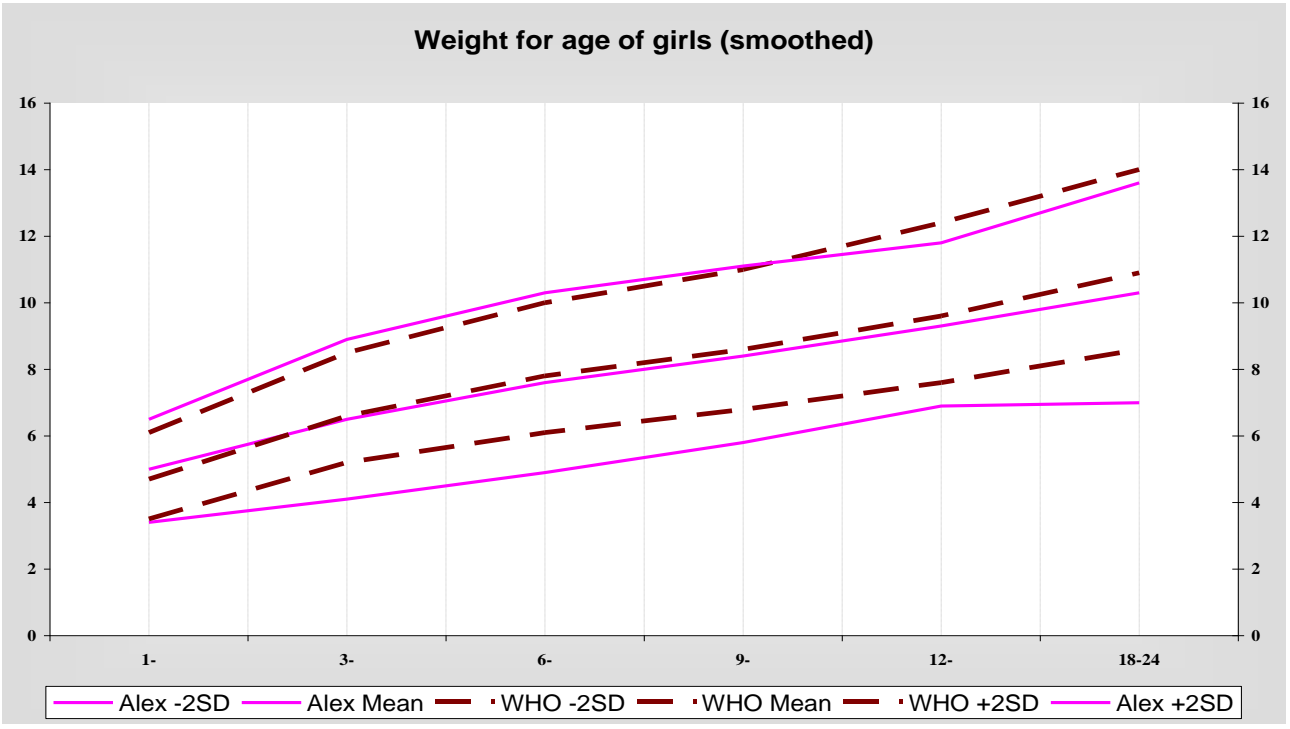

Figure (5): Comparison of the WHO and the present weight-for-age Z-score curves for girls.

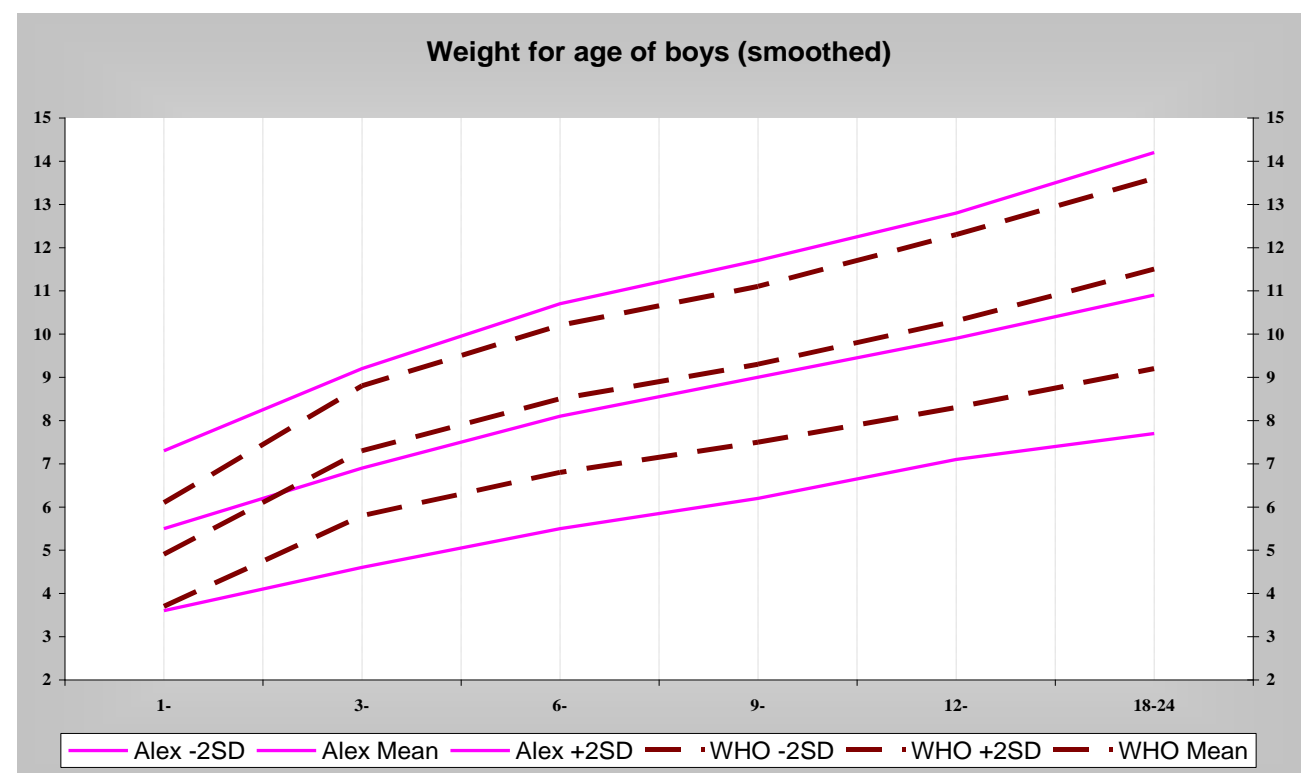

Figure (6): Comparison of the WHO and the present weight-for-age Z-score curves for boys. 
Table (3): Comparison of the WHO and the Present Length -for-Age Z-Score Curves for Girls.

\begin{tabular}{|c|c|c|c|c|c|c|}
\hline & \multicolumn{6}{|c|}{ Smoothed length for female } \\
\hline \multirow{2}{*}{ Age } & \multicolumn{5}{|c|}{ Alexandria } & \multicolumn{3}{c|}{ WHO } \\
\cline { 2 - 7 } & -2 SD & Mean & +2 SD & -2 SD & Mean & +2 SD \\
\hline $1-$ & 47.3 & 54.5 & 61.8 & 45.4 & 49.1 & 52.9 \\
\hline $2-$ & 48.7 & 57 & 65.2 & 49.8 & 53.7 & 57.6 \\
\hline $3-$ & 50.2 & 59.2 & 68.2 & 53 & 57.1 & 61.1 \\
\hline $4-$ & 51.7 & 61.2 & 70.8 & 55.6 & 59.8 & 64 \\
\hline $5-$ & 53.3 & 63.1 & 73 & 57.8 & 62.1 & 66.4 \\
\hline $6-$ & 54.9 & 64.9 & 74.8 & 59.6 & 64 & 68.5 \\
\hline $7-$ & 56.5 & 66.4 & 76.4 & 62.7 & 67.3 & 71.9 \\
\hline $8-$ & 58 & 67.9 & 77.8 & 64 & 68.7 & 73.5 \\
\hline $9-$ & 59.5 & 69.2 & 79 & 65.3 & 70.1 & 75 \\
\hline $10-$ & 60.9 & 70.5 & 80 & 66.5 & 71.5 & 76.4 \\
\hline $11-$ & 62.3 & 71.6 & 80.9 & 67.7 & 72.8 & 77.8 \\
\hline $12-$ & 65 & 74 & 82.9 & 70.5 & 75.5 & 80.7 \\
\hline $15-$ & 66.8 & 76.3 & 85.7 & 73.5 & 78.8 & 84.3 \\
\hline $18-$ & 66.5 & 78.2 & 89.9 & 76.1 & 81.9 & 88.1 \\
\hline $21-24$ & 64.1 & 79.7 & 95.3 & 79.2 & 85.7 & 92.3 \\
\hline
\end{tabular}

Table (4): Comparison of the WHO and the Present Length-for-Age Z-Score Curves for Boys.

\begin{tabular}{|c|c|c|c|c|c|c|}
\hline & \multicolumn{6}{|c|}{ Smoothed length for male } \\
\hline \multirow{2}{*}{ Age } & \multicolumn{3}{|c|}{ Alexandria } & \multicolumn{3}{c|}{ WHO } \\
\cline { 2 - 7 } & -2 SD & Mean & $+2 S D$ & $-2 S D$ & Mean & +2 SD \\
\hline $1-$ & 47.6 & 55.3 & 63.1 & 46.1 & 49.9 & 53.7 \\
\hline $2-$ & 49.9 & 58 & 66 & 50.8 & 54.7 & 58.6 \\
\hline $3-$ & 52 & 60.4 & 68.7 & 54.4 & 58.4 & 62.4 \\
\hline $4-$ & 53.8 & 62.5 & 71.2 & 57.3 & 61.4 & 65.5 \\
\hline $5-$ & 55.3 & 64.3 & 73.4 & 59.7 & 63.9 & 68 \\
\hline $6-$ & 56.6 & 66 & 75.5 & 61.7 & 65.9 & 70.1 \\
\hline $7-$ & 57.7 & 67.5 & 77.3 & 63.3 & 67.6 & 71.9 \\
\hline $8-$ & 58.6 & 68.8 & 79 & 64.8 & 69.2 & 73.5 \\
\hline $9-$ & 59.4 & 70 & 80.5 & 66.2 & 70.6 & 75 \\
\hline $10-$ & 60.2 & 71.1 & 81.9 & 67.5 & 72 & 76.5 \\
\hline $11-$ & 60.8 & 72 & 83.2 & 68.7 & 73.3 & 77.9 \\
\hline $12-$ & 62.3 & 74.1 & 86 & 72.6 & 77.4 & 82.4 \\
\hline $15-$ & 64.4 & 76.6 & 88.8 & 75.5 & 80.7 & 85.9 \\
\hline $18-$ & 67.6 & 79.5 & 91.4 & 78.2 & 83.7 & 89.3 \\
\hline $21-24$ & 71.6 & 82.7 & 93.7 & 80.3 & 86.4 & 91.4 \\
\hline
\end{tabular}




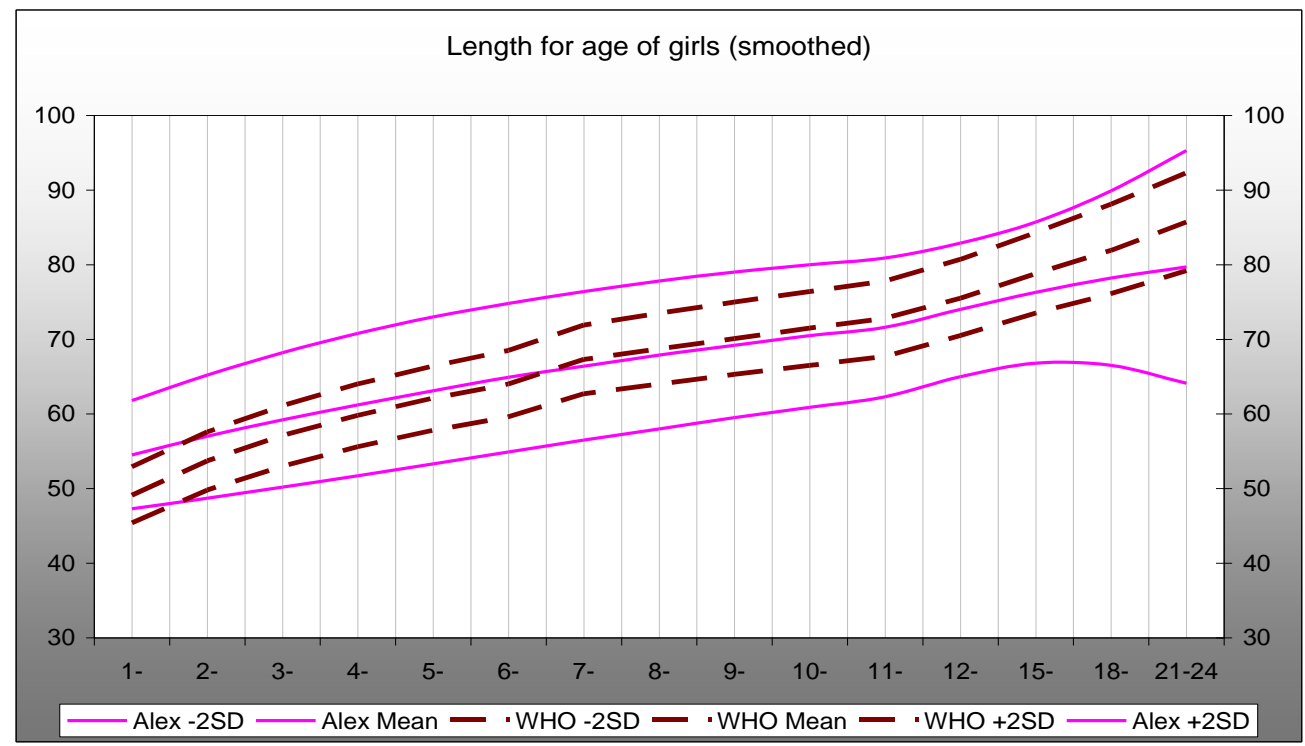

Figure (7): Comparison of the WHO and the Present Length -for-Age Z-Score Curves for Girls

\section{Length for age of boys (smoothed)}

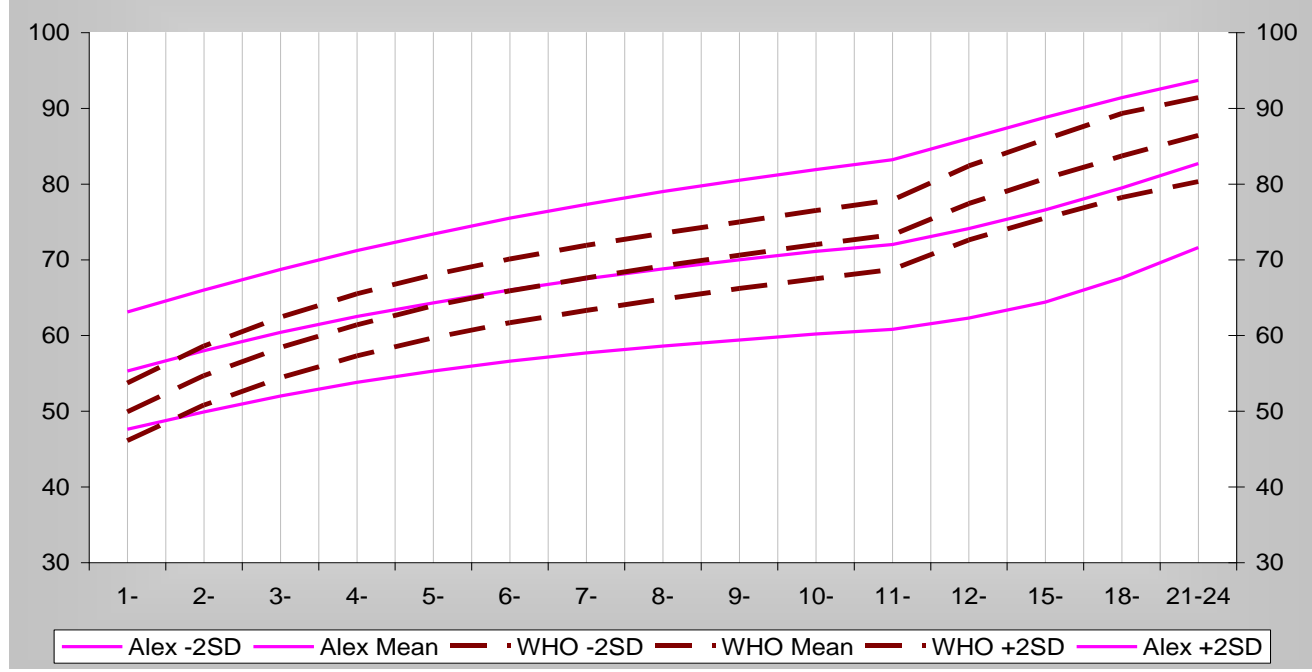

Figure (8): Comparison of the WHO and the Present Length-for-Age Z-Score Curves for Boys 
DISCUSSION:

There are important differences between the WHO standards 2006 and the NCHS/WHO reference that vary by age group, growth indicator, and specific percentile or Z-score curve. For weight-forage, the divergence in the shape of the WHO curves is likely due to issues related to study design (i.e., sample size and measurement intervals) and characteristics of the sample, mainly differences in type of feeding. ${ }^{(16)}$

A similar results reported by the present curves, where differences are particularly important during infancy, likely due to the inclusion of only breast-fed infants in the WHO sample and the inclusion of formulafed infants in the present sample. Moreover, differences in measurement intervals between the two sets of curves (every 2 weeks in the first two months and monthly thereafter in the WHO standards vs. every 3 month in the present sample) in a period of rapid growth also may explain the divergent growth patterns. ${ }^{(14)}$ Differences in the variability of normal growth depicted by the WHO standards and the NCHS reference, the present curves likely are the result of the prescriptive approach and updated analytical methods on which the WHO standards are based. (15) The difference in the shapes of the weight-based curves makes the interpretation of growth performance strikingly different depending on whether the WHO standard or other reference is used, which in turn has important implications for the advice given to mothers concerning lactation performance and the introduction of complementary foods.

Using the new WHO growth standards increased the estimated prevalence of malnutrition in early infancy; this difference was not found at one year of age. But the magnitude of this increase depends on the nutritional status of the population under consideration. ${ }^{(16-19)}$ 
The estimated prevalence of life, but once additional feeding is underweight (weight-for-age,-2 z-score) necessary some of them start to become and stunting (length-for-age,-2 z-score) underweight. So, for predominantly breastwere considerably greater in the first 5 fed infants, the WHO 2006 curves for age 0 months of life when using the WHO to 24 months, based on longitudinal data, standards than with the NCHS / WHO reference $(16,17)$ but the proportion of underweight children did not seem to accelerate with age, thus revealing that the classical growth faltering pattern of an increasing proportion of underweight children with age associated with the previously used reference was not observed once the WHO 2006 standards were applied.(20) In contrast, the present study estimated a higher prevalence of underweight in early infancy that increased with age of the child all through 24 months compared to WHO standards. This growth faltering pattern has been described in numerous nutritional surveys all over the world. $(16,17,20,21)$. The common interpretation was that children develop well while being fully breast-fed in the first months of their are the best choice, because fewer exclusively breast-fed infants would be categorized as underweight. As the WHO 2006 curves a growth standard for all infants, then there would be less concern for the exclusively formula-fed infant at age 5 months with complementary food introduced by 4 months. ${ }^{(20)}$ Those infants constitute a considerable proportion of the present sample.

Breast-fed infants (WHO standards 2006) experience greater linear growth than the present median until age 24 month. Breast-fed infants grow more rapidly in the first 2 month of life and less rapidly from 3 to 12 month in relation to the present HA curves. Repeated acute infections after one year of age could explain the mean LA z-score declines until 
24 month. The growth trajectories indicate that infants in the WHO standards 2006 are taller than the present curves.

Overall, the median of the present sample seems to be similar or better than that of the WHO standards. While, the apparent differences observed in the $(<-$ 2SD) \& (> +2SD).

\section{Conclusion and Recommendations}

As was the case when compared $\mathrm{WHO}$ standards 2006 with the NCHS/WHO reference. There are notable differences in the growth trajectory of breastfed infants examined through WHO standards against the present curves. A reference based on healthy breastfed infants is required if the growth patterns of infants following international feeding recommendations are to be correctly assessed. So, the WHO 2006 curves for age 0 to 24 months, based on longitudinal data, are the best choice.

\section{REFRENCES:}

1. Vignerova J. Economics and Human Biology.doi:10.1016/j.ehb. 2008. 11.001 journal homepage: Available from: http://www. elsevier.com/locate/ehb
2. WHO. Foreword. Acta Pædiatrica. 2006; 450: 5- 6.

3. Glewwe P, Miguel E A. The impact of child health and nutrition on education in less developed countries. In: Schultz T P, Strauss JA. (Eds.), Handbook of development economics. eds 4 th. Elsevier: Amsterdam. (Chapter 56), 2007: page. 3561-3606.

4. de Onis M, Garza C, Habicht J-P. Time for a new growth reference. Pediatrics. 1997; 100(5). Available at: http://www.pediatrics.org/cgi/

5. Garza C, de Onis M. WHO Multicentre Growth Reference Study Group. Rationale for developing a new international growth reference. Food Nutr Bull. 2004; 25 (S 1):S5-14.

6. WHO Multicentre Growth Reference Study Group. WHO Child Growth Standards: length/height-for-age, weight-for-age, weight-for length, weight-for-height and body mass index-for-age: methods and development. Geneva: World Health Organization, 2006.

7. WHO Multicentre Growth Reference Study Group. WHO Child Growth Standards based on length/height, weight and age. Acta Paediatr Suppl. 2006; 450: 76-85.

8. Moussa1 WA. Two decades of nutrition assessment in the Eastern Mediterranean Region: scope, methodologies and dissemination. Eastern Mediterranean health journal. 2004;10 (6):704-15

9. de Onis M, Wijnhoven TM, Onyango M. Worldwide practices in child growth monitoring. J Pediatr. 2004; 144: 461-5.

10. UNICE. State of the World's Children 2007. Women and children: the double dividend of gender equality. New York: UNICEF; 2007, p. 160

11. Bhandari N, Bahl R, Taneja S, de Onis M, Bhan K. Growth performance of 
affluent Indian children is similar to that in developed countries. Bull WHO. 2002;80, 189-95

12. El-Sayed N, Mohamed A G, Nofal L, Mahfouz A, Abou Zeid H. Malnutrition among pre-school children in Alexandria, Egypt. J Health Popul Nutr. 2001;19(4):275-80

13. WHO. A Growth Chart for International Use in Maternal and Child Health Care: Guidelines for Primary Health Care Personnel. Geneva, Switzerland: WHO; 1978

14. WHO Multicentre Growth Reference Study Group. Enrollment and baseline characteristics in the WHO Multicentre Growth Reference Study. Acta Paediatr Suppl. 2006; 450:7-15.

15. de Onis M, Garza C, Victora CG, Onyango AW, Frongillo EA, Martines J, WHO Multicentre Growth Reference Study Group. The WHO Multicentre Growth Reference Study: planning, study design and methodology. Food Nutr Bull . 2004; 25 Suppl 1:S15-26.

16. de Onis M, Onyango AW, Borghi E, Garza C, Yang H, WHO Multicentre Growth Reference Study Group. Comparison of the World Health Organization (WHO) Child Growth Standards and the National Center for Health Statistics/WHO international growth reference: implications for child health programmes. Public Health Nutr. 2006; 9(7): 942-7.

17. de Onis M, Garza C, Onyango AW, Borghi E. Comparison of the WHO child growth standards and the CDC 2000 growth charts. J Nutr. 2007; 137: 144-8.

18. Seal A, Kerac M. Operational implications of using 2006 World Health Organization growth standards in nutrition programmes: Secondary data analysis. Brit Med J.2007; 334: 733.

19. Prost MA, Jahn A, Floyd S, Mvula H, Mwaiyeghele E, Mwinuka V.et al. Implication of new WHO growth standards on identification of risk factors and estimated prevalence of malnutrition in rural malawian infants. PLoS ONE.2008; 3(7): e2684. doi:10.1371/journal.pone.0002684

20. de Onis M, Onyango AW. The Centers for Disease Control and Prevention 2000 growth charts and the growth of breastfed infants. Acta Paediatr. 2003; 92: 413-9.

21. Prinja S, Thakura J, Bhatiab S. Pilot testing of WHO Child Growth Standards in Chandigarh: implications for India's child health programmes. Bull World Health Organ. 2009; 87: 410-7. 